* Doutorando e Mestre em Direito Público (2014) pela Universidade do Vale do Rio dos Sinos - UNISINOS. Pesquisador do Grupo Transdisciplinar de Pesquisa Jurídica para Sustentabilidade - GTJUS (CNPq) da Faculdade de Direito - FADIR da Universidade Federal do Rio Grande - FURG

E-mail: alexandremichaello@ yahoo.com.br

\footnotetext{
** Doutor pela Ecole des Hautes Etudes en Sciences Sociales de Paris (1989) com Pósdoutorado em Sociologia do Direito pela Universita degli Studi di Lecce. Professor Titular do Programa de Pós-graduação em Direito (Mestrado e Doutorado) da Universidade do Vale do Rio dos Sinos.
}

E-mail: leonel@unisinos.br

\section{Estado, Surveillance e Risco: Caminhos Tortuosos em Tempos de Relativização da Democracia na ESTEIRA DA TECNOLOGIA}

\author{
State, Surveillance And Risk: Tortuous Paths In \\ Times Of The Relativization Of Democracy In The \\ TECHNOLOGICAL ERA
}

\section{Carlos Alexandre Michaello Marques* Leonel Severo Rocha**}

Como citar: MARQUES, Carlos Alexandre Michaello; ROCHA, Leonel Severo. Estado, surveillance e risco: caminhos tortuosos em tempos de relativização da democracia na esteira da tecnologia. Revista do Direito Público, Londrina, v. 14, n. 2, p. 68-90, ago. 2019. DOI: 10.5433/24157-108104-1.2019v14 n2p. 68. ISSN: 1980-511X

Resumo: $O$ presente trabalho pretende demonstrar a atualidade e a importância do debate das crises do Estado para Teoria do Estado, bem como o enfrentamento teórico das bases da estatalidade. Ademais, foram abordadas temáticas indispensáveis à compreensão do Estado, como a Modernidade (Sólida e Líquida), a Globalização e suas consequências e o Capitalismo e o diálogo com os poderes públicos e privados. Diante do cenário posto, se avançou no tocante ao fenômeno da Surveillance e a incapacidade do Estado de compreender suas dimensões. No mesmo sentido, se buscou esclarecer as relações entre Risco e Tecnologia, para assim compreender como os fluxos globais escapam da regulação do Estado territorializado. Por fim, se discutiu os efeitos à democracia e qual o lugar/papel da mesma na reconstrução de um cenário pós-crise. A pesquisa se utilizou da técnica de pesquisa bibliográfica e documental.

Palavras-chave: Estado. Surveillance. Risco.

Abstract: This paper examines the importance of the ongoing
academic debate regarding the crisis of the State from the
perspective of the Theory of the State, as well as the theoretical
confrontation of the concept of statehood. Moreover, subjects
that are essential for understanding the State, such as Modernity
(Solid and Liquid), Globalization, its consequences, Capitalism,
and its dialogue with public and private entities, were also 
analyzed. In light of this context, there has been significant progress regarding the phenomenon of Surveillance and the inability of the State to understand its dimensions. In this sense, this research sought to clarify the relationship between risk and technology, in order to better understand how global issues escape the regulation of the territorialized state. Finally, the effects of democracy and its place/role in the reconstruction of a post-crisis scenario were discussed. This study utilizes literature review as its primary method of analysis.

Keywords: State. Surveillance. Risk. 


\section{INTRODUÇÃO}

O Estado Moderno tem sofrido diversas transformações desde seu ponto de minerva póswestfaliano, a Teoria do Estado, por assim dizer tradicional, não consegue corresponder aos desafios que a contemporaneidade lhe impõe, seja aqui considerado como paradigma a concepção de pósmodernidade (BAUMAN, 1999b), modernidade líquida (BAUMAN, 2001), alta modernidade (GIDDENS, 1991), modernização reflexiva (GIDDENS; LASH; BECK, 2012) ou mesmo modernidade reflexiva. As questões que se observam neste cenário produzem a identificação de diversas crises do Estado - Crise Conceitual, Estrutural, Constitucional e Política, todas com seus desdobramentos (MORAIS, 2005, 2011).

Os problemas que tradicionalmente eram enfrentados no âmbito da territorialidade tendem a escapar da capacidade estatal, a democracia, seja como objetivo ou como valor, passa a ser debatida, não mais no mesmo cenário e sobre as mesmas bases. A globalização/mundialização/ internacionalização impulsiona modificações que os Estados não estão preparados para absorver, fazendo com que o modelo econômico capitalista comine suas regras em face da incapacidade estatal, fragilizando o processo democrático.

É, justamente, neste entrecruzar de desafios que o pool tecnológico se apresenta como um desafio ainda maior, pois, neste contexto, os Estados apresentam um gap colossal. As denominadas novas tecnologias de controle deixam o Estado em constante sobressalto, eis que o próprio fenômeno da Surveillance, até o momento não foi bem compreendido, como será analisado. Ademais, este imprevisto para a estatalidade, também alija a sociedade do processo democrático e, ignora a percepção dos riscos frente a ambivalência natural da técnica.

Desse modo, é que se pretende percorrer pelas crises do Estado Contemporâneo, a fim de identificar dificuldades como manter o conceito tradicional de soberania, ou mesmo compreender os avanços da tecnologia fora do conceito de territorialidade. Não obstante, é da mesma forma indispensável o debate da democracia (no pós-cenário), bem como do capitalismo globalizado, eis que os fluxos globais não têm respeitado fronteiras e/ou limitações de quaisquer natureza tradicionalmente impostas pelos Estados.

Com efeito, merece atenção especial a compreensão do fenômeno da Surveillance (MENEZES NETO, 2016b) como uma categoria significante ao Direito e à Teoria do Estado, e o entrelaçamento das questões da Tecnologia e do Risco que lhe são inerentes. Neste sentido, é mister ao fim e ao cabo, confrontar as fragilidades do Estado Contemporâneo, não apenas para uma eventual superação da figura do mesmo, um fim do Estado, mas para racionalizar um câmbio de horizontes possíveis neste cenário de crises.

Por fim, a preocupação que norteará todo este estudo é o de tentar (re)alocar e/ou (r) estabelecer o ponto fulcral da democracia nas transformações provocadas no Estado. Assim, o grande questionamento que se impõe é, se o que restar deste processo ainda poderá ser considerado um Estado nos termos da Teoria do Estado Clássica, seja por uma nova conformação, seja pelo fortalecimento de agentes não estatais ou subestatais neste cenário em pesquisa. Para tanto, se 
utilizou da técnica de pesquisa bibliográfica e documental.

\section{AS CRISES DO ESTADO MODERNO/CONTEMPORÂNEO}

As discussões sobre o Estado sempre ocuparam um lugar de destaque no ambiente acadêmico, seja na própria Teoria do Estado ou por sua indispensabilidade em outros campos do Direito, pois é imperioso o conhecimento desta instituição político-jurídica de organização de poder à Ciência Jurídica. Assim, de um modo geral foi estabelecida sua construção sustentada em três elementos clássicos, quais sejam: território, povo e governo. Neste sentido, um passo importante é de imediato diferenciá-lo da pré-estatalidade medieval, pois o surgimento da "[...] nova forma de organização política que é o Estado foi, nos países europeus, ligada a um conjunto de transformações que marcam a entrada desses países na era da 'modernidade'." (CHEVALLIER, 2009, p. 13).

Os traços marcantes da modernidade (cisão do espaço-tempo) são sem dúvida identificáveis totalmente com o Estado ${ }^{1}$, pois por intermédio desta se inaugura o primado da razão (Ciência e Progresso) e do indivíduo (Cidadão), substituindo desta forma as estruturas transitórias e pessoalizadas nas relações de poder, por estruturas rígidas, próprias daquele momento do paradigma moderno, onde a generalidade e impessoalidade assumiam a gestão do poder, se convertendo em uma verdadeira institucionalização do mesmo. É neste contexto que o surgimento do arquétipo Estado-Nação, que pelos séculos foi espraiado à outros diversos lugares do globo, pelo conhecido processo colonizador, que não é possível - igualmente dissociar da modernidade ocidental -, se consolidou. Neste sentido:

Foram os seguintes os processos mais significativos na constituição do Estado Nacional: a) a crescente coincidência entre fronteiras territoriais e um sistema uniforme de leis; b) a criação de novos mecanismos de elaboração e imposição de leis; c) a centralização do poder administrativo; d) o estabelecimento de impostos e de gestão do sistema fiscal; e) a criação de Forças Armadas nacionais; f) a constituição da diplomacia para regular as relações entre Estados Nacionais. (FORJAZ, 2000, p. 41).

Assim, nesta quadra da história institucional, o surgimento e a consolidação da instituição político-jurídica denominada de Estado, bem como seus múltiplos modelos alargados - o que de toda sorte impediria até mesmo o que se conhece como uma Teoria Geral do Estado -, permitiram

\footnotetext{
1 Neste sentido, para Jacques Chevallier (2009, p. 15, grifo do autor) as: “[...] características essenciais do modelo estatal são a tradução dos valores subjacentes à modernidade: a institucionalização do poder, quer dizer a inscrição das relações de dominação política num quadro geral e impessoal; a produção de um novo quadro de submissão, a "cidadania" sendo concebida como uma ligação excludente, incompatível com a existência de submissões paralelas ou concorrentes; o estabelecimento do monopólio da força, o Estado sendo entendido, dentro das "fronteiras" delimitantes do campo de sua "soberania", a única fonte do direito e a única habilitada a fazer o uso dos meios de coerção; a consagração de um princípio fundamental de unidade, unidade de valores resultantes da pertinência a uma esfera pública posta como distinta do resto da sociedade, unidade do direito estatal, apresentando-se como uma totalidade coerente, uma "ordem" estruturada, unidade do aparelho encarregado de colocar em operação o poderio do Estado. Por todos esses elementos, a construção do Estado aparece bastante indissociável de uma modernidade da qual ela é, por vezes, o reflexo e o valor."
} 
inicialmente abarcar a concepção de soberania (Hobbes, Locke e Rousseau) e, com isto compreender o locus da democracia. Todavia, diante da relevância, em especial, a análise e compreensão das crises nas quais o Estado tem constantemente experimentado uma ligeira impotência de resolução imediata dos desafios, cumpre avançar no que se denominou como Estado Liberal e Estado Social, com vistas até mesmo consolidar as bases à um câmbio de horizontes plausível no contexto.

Como é possível inferir acerca deste processo de constituição, o Estado como "[...] o monopolizador do poder, o detentor da soberania, o depositário da coação incondicionada, tornase, em determinados momentos, algo semelhante à criatura que na imagem bíblica, se volta contra o Criador." (BONAVIDES, 2011, p. 41). Nesta esteira, em movimento antagônico se vislumbra a noção de Estado de Direito ${ }^{2}$ ao receber os aportes do liberalismo, em uma clara orientação de limitação estatal em favor do indivíduo, um Estado submetido ao império da lei, o que poderia ser traduzido como o segundo passo do Estado Moderno.

Assim, também permanecem evidenciadas algumas das principais características do Estado Liberal, como a separação entre o Estado e a Sociedade, e a Separação de Poderes (funções/ atribuições) no que concerne as palavras de Avelãs Nunes (2007). Não obstante, é um equivoco bastante comum a associação imediata do Estado de direito “[...] que alcançou sua experimentação histórica na Revolução Francesa [...]” (BONAVIDES, 2011, p. 42), com os objetivos da burguesia da época (derrubada da aristocracia-absolutista), pois este mesmo Estado de direito "[...] foi também um instrumento ao serviço da burguesia para, num segundo momento, tentar consolidar e perpetuar a sua posição de classe dominante [...]" (AVELÃS NUNES, 2007, p. 1). As pretensões claramente oriundas de uma nova divisão de classes, onde foram colocados lado-a-lado o capital e o trabalho não permitiram a correspondências amiúde das aspirações de outrora acerca da igualdade na concepção liberal clássica.

O evidente fracasso da doutrina liberal sobre o Estado de Direito faz com que nas palavras de Avelãs Nunes (2007) haja uma emergência do Estado Social, eis que neste sentido cresce a necessidade de uma participação mais efetiva do Estado neste modelo, com vista a promover justiça social. Todavia, o Estado Social ${ }^{3}$ mesmo representando uma transformação significativamente relevante, no tocante a superestrutura do Estado Liberal, o grande signo que ainda resta neste novo cenário "[...] é que ele conserva sua adesão à ordem capitalista, princípio cardeal a que não renuncia." (BONAVIDES, 2011, p. 184). As promessas advindas deste modelo de Estado são muitas e as frustrações igualmente incomensuráveis, pois a cada momento que se encontrava atendida uma demanda eventual, momento seguinte outra lhe ocupa o lugar, e com isto surgem as

2 "Talvez possamos admitir que o estado de direito assenta sobre três princípios essenciais: 1) o princípio democrático, que, por oposição ao princípio monárquico do estado absolutista, pressupõe a soberania popular; 2) o princípio liberal, implicando a ideia da separação entre o estado e a sociedade (a sociedade civil, no seio da qual se desenvolve a economia, como actividade que apenas diz respeito aos privados); 3) o princípio do direito, que implica a sujeição do estado ao direito, i.é, às leis aprovadas no parlamento." (AVELÂS NUNES, 2007, p. 1, grifo do autor).

3 "Do que se trata é de articular direitos, liberdades e garantias (direitos cuja função imediata é proteção da autonomia da pessoa) com direitos sociais (direitos cuja função imediata é o refazer das condições materiais e culturais em que vivem as pessoas); de articular igualdade jurídica (à partida) com igualdade social (à chegada) e segurança jurídica com segurança social; e ainda de estabelecer a recíproca implicação entre liberalismo político (e não já, ou não já necessariamente, económico) e democracia, retirando-se do princípio da soberania nacional todos os seus corolários (com a passagem do governo representativo clássico à democracia representativa).” (MIRANDA, 2011, p. 40, grifo do autor). 
crises.

De acordo com Pfetsch (1998, p. 112-113): “John Hertz falava, já em 1969, da 'crise do Estado-nação territorial' e Ernst-Otto Czempiel, no mesmo ano, referia-se à 'soberania anacrônica'; [...]" No Brasil, a temática foi inserida por Bolzan de Morais em 1996 (MENEZES NETO, 2016b), e passou a inaugurar um campo de pesquisas na Teoria do Estado. Não obstante sejam (e serão aqui) as crises do Estado abordadas de forma separada, as mesmas compõe um mosaico único (MORAIS, 2005).

A primeira peça deste mosaico diz respeito a Crise Conceitual, ou a interrogação do Poder como Soberania, soberania esta que perceptivelmente sofreu transformações até sua configuração atual, tendo em vista que era "[...] tradicionalmente tida como una, indivisível, inalienável e imprescritível." (MORAIS, 2011, p. 27). O próprio transpassar do Estado Liberal ao Estado Social deu seu contributo à transformação da soberania, eis que não é vista mais como poder incontrastável, mas como atrelada à um processo de cooperação, fruto em grande medida da flexibilização das fronteiras físicas. ${ }^{4}$ Ademais, há de se considerar que os processos de globalização/mundialização, integrações regionais e comunidades supranacionais também passam a pressionar o esfalfado conceito tradicional de soberania.

Este cenário de pressões ${ }^{5}$, embora não seja de todo estranho ao Estado, pois o mesmo já o enfrenta interna e externamente deste sua concepção moderna, pode igualmente ser desafiador, por ser fruto da própria tentativa de resistência aos influxos. Os "[...] Estados são capturados na rede dos poderes públicos supraestatais, por eles próprios constituída [...]”, como “[...] o desenvolvimento de organizações intergovernamentais, gerais e especiais, mundiais e regionais." (CASSESE, 2010, p. 57). Este processo é um esfacelamento da soberania, por vezes pelo Estado, que redimensiona ou torna as fronteiras permeáveis, o que impossibilita a material aplicação do direito em sua delimitação geográfica.

Um segundo fragmento deste mosaico é a denominada Crise Estrutural, ou também identificada com Crise do Estado Social que se desdobra em três frentes, a Crise Fiscal-Financeira, ou seja, a dificuldade do Estado se financiar e continuar atendendo suas tarefas sociais; a Crise Ideológica, que é uma representação da dificuldade de compatibilização entre a ampliação do acesso (demandas sociais qualitativas e quantitativas) e a burocratização (tecnoburocracia) como meio de resposta do Estado às demandas promovidas no campo político; e finalmente a Crise Filosófica, a qual "atinge exatamente os fundamentos sobre os quais se assenta o modelo do BemEstar Social. Aponta para a desagregação da base do Estado Social, calcada esta no seu fundamento a solidariedade [...]." (MORAIS, 2011, p. 48, grifo do autor).

Com isto, se alcança a pedra medial no mosaico de crises estabelecido por Morais (2005,

4 Neste sentido Morais (2011, p. 29) afirma que: “Uma soberania pós-moderna cujas fronteiras, aquelas próprias do modelo moderno do Estado, seriam flexíveis, onde sem que se saiba ao certo onde se iniciam e onde terminam, se é que se iniciam ou terminam, em algum lugar demarcado.".

5 "Não se deve esquecer que fortes investimentos feitos em um Estado dão suporte a seu regime, enquanto a redução dos investimentos o enfraquece, podendo até mesmo levá-lo à derrocada. Outrossim, em vista das intrincadas teias econômicas, um boicote econômico - caso seja efetuado com eficácia por todos os Estados - pode levar qualquer Estado a curvar-se." (HÖFFE, 2005, p. 472). 
2011), a Crise Constitucional ou Institucional, que é oriunda de uma pulsão do neoliberalismo tendente ao processo de desconstitucionalização. Além disto, cumpre destacar um processo de fragilização/fragmentação do Estado frente as pretensões colonizadoras de uma economia capitalista (capitalismo financeiro globalizado), uma vez que: “[...] este ambiente de crise proporciona e repercute na própria funcionalidade do Estado [...], bem como com uma disputa intestina, como percebemos sob a nomenclatura de crise funcional [...]" (MORAIS, 2011, p. 56, grifo do autor).

Penúltima peça desta estrutura, a Crise funcional ou perda de exclusividade, é fundamentada em uma multiplicidade de locais que emanam poder, é uma verdadeira perda de referência, pois o Estado visto como centralizador e exclusiva fonte de poder, se esvanece sensivelmente (MORAIS, 2011). Uma das situações que se apresentam é a hipertrofia do judiciário, ao avançar para além das funções intrínsecas ao modelo tripartite clássico, promovendo com isto, por exemplo a “[...] judicialização da política, em especial desde a centralidade assumida com a ascensão da função jurisdicional, particularmente ante o crescimento do seu papel como jurisdição constitucional." (MORAIS, 2011, p. 56, grifo do autor). Da mesma forma, a crise funcional também pode ser notada externamente à própria estrutura do Estado, quando este passa a ser claramente confrontado com entidades não estatais para fazer valer a lei em seu território. ${ }^{6}$

A última parte que completa o mosaico diz respeito à Crise Política ou da Representação, o mecanismo da democracia moderna ${ }^{7}$, que por sua vez também não transpõe de maneira ilesa o cenário até o momento apresentado (MORAIS, 2005). Neste contexto, há uma clara dissonância entre o modelo representativo e os anseios sociais dos representados, isto frente a verdadeira incapacidade do sistema político de compreender as transformações que constituem a complexa sociedade contemporânea, e suportar as influências/interferências do capitalismo financeiro, se convertendo este em um verdadeiro fantoche diante da apatia política gerada neste processo. ${ }^{8}$ Assim, por ser uma

[...] construção humana e precária, o modelo estatal vive em crise desde sua fundação. Entretanto, as análises mais recentes parecem ter o fenômeno da globalização como um traço comum na discussão a respeito do destino do Estadonação, especialmente levando-se em conta que o mundo atual é caracterizado pela expansão global da tecnologia da informação e da riqueza, fenômenos que tendem a desintegrar a compreensão de fronteiras espaço-temporais. (MENEZES NETO, 2016a, p. 40-41).

O mosaico de crises, apresentado em sua configuração pentavalente, recai sobre o Estado

6 Neste sentido, acrescenta Sabino Cassese (2010, p. 32) “A fragmentação dos poderes públicos é um dos principais problemas dos ordenamentos modernos. Nos ordenamentos unitários, a instituição e posterior multiplicação de entidades públicas nacionais e o surgimento de figuras híbridas, constituídas de organismos semipúblicos, tiraram o sono dos cultores do Estado.”.

7 Pierre Rosanvallon (2010, p. 304): “[...] la democracia contemporánea puede ser comprendida como la forma política que reúne, aclimatándolas y desarrollándolas, las múltiples historias de la liberdad, de la emancipacción y de la autonomía que han marcado la expericencia humana."

8 Assim, esclarece Morais (2011, p. 72, grifo do autor): “ [...] em contextos econômicos ou de pautas do capitalismo financeiro, os mercados alteram seus humores com a rapidez volátil da transferência eletrônica de ativos financeiros, fazendo com que as opções políticas presentes no jogo eleitoral deem soluções idênticas às questões que lhe são postas, desaparece o caráter representativo do sistema, diluído na homogeneidade de respostas. 
Contemporâneo $^{9}$, especialmente como resultado da própria Globalização que o confrontou às insuficiências apresentadas em solucioná-las. Na emergência de uma Revolução Industrial 4.0, de um crescimento exponencial das novas tecnologias, que percorrem o globo em velocidades inimagináveis é que se conforma a premência de desenvolver os contextos fundantes das referidas crises. Estado, Modernidade, Globalização e Capitalismo, signos que não se contentam com análises isoladas por tudo que já foi referido e o que ainda se está por discutir e, neste ínterim serão melhor posicionados a seguir em suas imbricações.

\section{MODERNIDADE, GLOBALIZAÇÃO E CAPITALISMO}

A Modernidade ${ }^{10}$ e o Estado, de acordo com a premissa que se partiu neste estudo, são inevitavelmente indissociáveis, assim como a emergência de um modo de produção capitalista, tendo em vista que a “[...] modernidade européia é inseparável do capitalismo.” (HARDT; NEGRI, 2001, p. 103) e a "disseminação das instituições modernas através do mundo foi originalmente um fenômeno ocidental" (GIDDENS, 1991, p. 74). O projeto/programa/paradigma moderno edificou uma série de promessas, as quais caberiam em grande parte ao Estado concretizar, por seu papel institucionalizador e centralizador do poder.

Todavia, como já é sabido o Estado em nenhum dos seus modelos conseguiu atender a totalidade de demandas da sociedade e, o Estado Social é um exemplo bastante evidente deste fracasso, em especial nos ditos países de modernidade tardia como é o caso na América Latina. Neste contexto, emerge o modelo do "[...] Estado Democrático de Direito, que busca assegurar as conquistas modernas e resgatá-las naquilo que ainda está incumprido, enfrentando, inclusive, suas próprias dificuldades [...] pela 'complexidade' da sociedade contemporânea.” (STRECK, MORAIS, 2008, p. 20).

É evidente que discorrer sobre a própria modernidade merece uma pesquisa de grande fôlego, mas sua relação de cooriginariedade ao Estado impõe algumas considerações sobre a própria modificação do paradigma. Diversos teóricos como Anthony Giddens, Jürgen Habermas, Ulrich Beck, Scott Lash, Zygmunt Bauman e Jean-François Lyotard se debruçaram sobre a temática com intenção de esclarecer o alcance do paradigma e suas transformações.

Como adverte Giddens (1991) não se pode compreender a modernidade em um plano linear, embora o autor não considere como relevante a imanência de uma pós-modernidade, enquanto paradigma no contexto contemporâneo. Todavia, seu pensamento remete à necessidade

\footnotetext{
9 "O Estado não poderia ser considerado como uma forma de organização política ultrapassada. Sem dúvida, ele é
} confrontado com novos dados que modificam o contexto de sua ação e, notadamente, à pressão cada vez mais

insistente exercida pela globalização: ele ainda persiste na atualidade como o princípio fundamental de integração das sociedades e o local de formação das identidades coletivas; e ele permanece o elemento essencial em torno do qual se organiza a vida internacional." (CHEVALLIER, 2009, p. 23).

10 Para Bauman (2001, p. 15, grifo do autor): "A modernidade começa quando o espaço e o tempo são separados da prática da vida e entre si, e assim podem ser teorizados como categorias distintas e mutuamente independentes da estratégia e da ação; quando deixam de ser, como eram ao longo dos séculos pré-modernos, aspectos entrelaçados e dificilmente distinguíveis da experiência vivida, presos numa estável e aparentemente invulnerável correspondência biunívoca. Na modernidade, o tempo, tem história, tem história por causa de sua 'capacidade de carga', perpetuamente em expansão - o alongamento dos trechos do espaço que unidades de tempo permitem 'passar', 'atravessar', 'cobrir' - ou conquistar.". 
de compreender as quatro dimensões institucionais/institucionalizadas da modernidade, o Capitalismo, o Industrialismo, a Vigilância e o Poder Militar. Outrossim, também é indispensável perceber que este estágio da modernidade não remete nem ao longe o atual momento, pois tem suas quatro garras cravadas na territorialidade.

Neste cenário, o Estado continua, em muito, operando a partir do modelo estabelecido no que poderia ser chamado segundo Giddens (1991) de baixa modernidade e não compreende com isto algumas das transformações introduzidas pelos processos de globalização/mundialização. De mesmo modo, o próprio modelo capitalista de produção também fez sua agenda se impor as condições estabelecidas pelos Estados e, aliado aos fluxos globais que desafiam a territorialidade, o cenário debatido das crises abriga às mais diversas tendências predatórias internas e externas à estatalidade.

O capitalismo, como referido, é estruturalmente também cooriginário ao Estado, pois foi por intermédio deste que seu florescer foi possível, mas é importante destacar que suas pretensões totalizantes foram além de um ambiente propício a sua racionalidade. É plausível de qualquer análise a identificação clara de que as pretensões do capitalismo moderno eram, não de operar na concepção do Estado-Nação, mas de modificá-lo até o limite de suas necessidades, qual seja, um deslocamento do sistema econômico da esfera da estatalidade.

Igualmente, é evidente que há uma influência em repensar os paradigmas, pois neste caso, a "[...] pós-modernidade, por outro lado, vive num estado de permanente pressão para se despojar de toda interferência coletiva no destino individual, para desregulamentar e privatizar [...]", (BAUMAN. 1999b, p. 26) algo que interessa claramente a um modelo de racionalidade capitalista. Esta influência do sistema econômico pressiona, a cada oportunidade, por fazer regredir os avanços assumidos pela estatalidade quando da assunção de funções sociais (Estado Social). Não obstante, cumpre relembrar, como acima referido, que o Estado Social não abandonou o modelo capitalista, algo que lhe custa caro na contemporaneidade, frente a incompatibilidade na raiz das intenções de ambos, mas que também apresentou questões de cooperação mútua. ${ }^{11}$

Contudo, outro fenômeno que acompanha de perto todo o cenário é o da globalização, que de igual turno não se apresenta como um consenso, nem ao menos, quanto ao seu surgimento, ou mesmo extensão. Algumas posições identificam-na frequentemente com as grandes navegações, outras com períodos pré-Estado Moderno ou até mesmo o início do século XX no pós-guerra. Todavia, em síntese apurada, a ideia da "[...] globalização é o do caráter indeterminado, indisciplinado e de autopropulsão dos assuntos mundiais; a ausência de um centro, de um painel de controle, de uma comissão diretora, de um gabinete administrativo.” (BAUMAN, 1999a, p. 66).

Assim como a modernidade, a globalização também ocupa distintos momentos identificáveis, sem uma linearidade dogmática ${ }^{12}$, o que resulta um equivoco comum de análises

11 "Como resultado da associação que se desenvolveu entre o capitalismo e o Estado-nação, as sociedades modernas diferem de todas as formas de civilização preexistentes. O Estado-nação e a empresa capitalista eram ambos depositários de poder, nos quais o desenvolvimento dos novos mecanismos de vigilância assegurava muito maior integração social através do tempo e do espaço do que havia sido previamente possível. "(GIDDENS, 2012, p. 144). 12 “A globalização não consiste em processo linear, com princípio, meio e fim, desenvolvendo-se por etapas e momentos previsíveis, explicáveis em virtude de relações de causa e efeito; trata-se de um fenômeno multidimensional, 
ao tentar congelar a observação em algum ponto e conceituar a globalização. "Globalização é, por conseguinte, um conceito abrangente de largo espectro (catch all concept), que pode ser livremente formulado de forma ampla ou restrita." (PFETSCH, 1998, p. 106, grifo do autor). E, neste sentido, o que efetivamente é relevante, não é a conceituação simples e objetiva ou alongada e detalhada, mas o seu impacto efetivo à Teoria do Estado na contemporaneidade, os desdobramentos, as suas consequências. "Com a globalização, no fim do século XX, novamente o Estado Nacional passa a sofrer a competição de instituições supranacionais ou transnacionais e subnacionais ou infranacionais de poder [...]". (FORJAZ, 2000, p. 42). Jacques Chevallier ao desenvolver sua explicação sobre a internacionalização/globalização afirmou que:

As fronteiras, físicas e simbólicas, que delimitavam a esfera de influência, o espaço de dominação do Estado, tornaram-se porosas: os Estados são atravessados por fluxos de todas as ordens, que eles são incapazes de controlar, de canalizar e, se necessário, conter; já não tendo controle sob as variantes essenciais que comandam o desenvolvimento econômico e social, a sua capacidade de regulação tornou-se, concomitantemente aleatória. (CHEVALLIER, 2009, p. 32)

O capitalismo na esteira dessas transformações potencializou sua influência e suas pretensões, mas não dispensou o Estado desta configuração - como alguns "futurólogos" gostam de alardear -, pois como acrescenta Anthony Giddens (1991), é necessário considerar assim como realizado no tocante a modernidade, as quatro dimensões da globalização ${ }^{13}$, que são justamente o sistema de Estado-Nação, a divisão internacional do trabalho, a Economia capitalista mundial e a Ordem militar. "O capital é globalmente móvel, o estado é territorialmente vinculado. É também o Estado que tem de assumir os custos decorrentes de tais decisões como, por exemplo, o desemprego gerado pela mobilidade global da produção.” (PFETSCH, 1998, p. 106) Assim, o Estado continua sendo importante locus na reconfiguração em curso promovida pela globalização.

Novamente, fica evidente que o Estado tem operado em nível distinto dos fenômenos que o atravessam, pois como refere Zygmunt Bauman (2001), já houve uma emergência da modernidade líquida, ocupando lugar da territorializada modernidade sólida ${ }^{14}$ de outrora. No entanto, não é perceptível que o Estado tenha compreendido esse transpassar da modernidade pesada para leve, da era do Hardware para a era do Software, bem como as mudanças que foram sendo transformadas ao longo do próprio paradigma moderno como a cisão espaço-tempo e a reconfiguração de suas relações na contemporaneidade.

A imbricação entre modernidade, capitalismo e globalização é inegável e, os desafios

envolvendo diversos domínios da atividade e da interação humanas, tornando-se, assim, em fenômeno complexo que exige a formulação de políticas públicas extremamente sofisticadas para a solução de seus problemas." (BARRETTO, 2013, p. 225).

13 “Os pensadores liberais e neoliberais de uma maneira geral tendem a diminuir excessivamente o peso e as funções do Estado, enquanto a postura inversa de defesa radical do estatismo pode redundar em dogmatismo, que ignora as recentes transformações do Estado provocadas pela globalização.” (FORJAZ, 2000, p. 48).

14 "A modernidade pesada foi a era da conquista territorial. A riqueza e o poder estavam firmemente enraizadas ou depositadas dentro da terra - volumosos, fortes e inamovíveis como os leitos de minério de ferro e de carvão. Os impérios se espalhavam, preenchendo todas as fissuras do globo: apenas outros impérios de força igual ou superior punham limites à sua expansão." (BAUMAN, 2001, p. 132). 
empreendidos à estatalidade só fazem aumentar, pois além de uma globalização econômicofinanceira - sem desconsiderar demais mutações como aponta Jacques Chevallier (2009) -, não bem compreendida, já se está na premência de fracassar frente a passagem à sociedade da informação. Não obstante, Zygmunt Bauman destaca que:

A integração e a divisão, a globalização e a territorialização, são processos mutuamente complementares. Mais precisamente, são duas faces do mesmo processo: a redistribuição mundial de soberania, poder e liberdade de agir desencadeada (mas de forma alguma determinada) pelo salto radical na tecnologia da velocidade. A coincidência e entrelaçamento da síntese e da dispersão, da integração e da decomposição são tudo, menos acidentais; e menos ainda passíveis de retificação. (BAUMAN, 1999a, p. 76, grifo do autor). ${ }^{15}$

Os impactos deste cenário são os mais diversos, pois a incompatibilidade entre o pensar o estágio/momento da modernidade pelo Estado, bem como a submissão à agenda da globalização capitalista não permitem enfrentar os desafios em sua plenitude. "De fato, a globalização é um paradoxo: é muito benéfica para muito poucos, mas deixa de fora ou marginaliza dois terços da população mundial.” (BAUMAN, 1999a, p. 79). Ademais, as respostas estão limitadas, pois não há um pensar novo ou um câmbio de horizonte imaginável. O momento atual dos paradigmas está dialogando com novas perspectivas tecnológicas, resultado de todo este processo exposto.

Assim, o espectro da Crise Conceitual insurge com maior intensidade, pois mesmo que ainda permaneça como um importante ator, "[...] já não consegue dar conta da complexidade das (des)estruturas institucionais que se superpõem hoje.” (MORAIS, 2011, p. 35). De igual modo, a Crise Institucional também pode e deve ser destacada, tendo em vista o próprio enfraquecimento estatal e os processos de desconstitucionalização agenciados pela corrente neoliberal que tenta reforçar suas posições no capitalismo financeiro globalizado contemporâneo. Além disto, as Crises Funcional e Política também são evidentemente, em especial nos problemas no campo da democracia que se apresentam na atualidade, mas não representam um fim do Estado. ${ }^{16}$

A democracia é que tem sido atingida com maior intensidade neste processo, seja pelo capitalismo globalizado (redução de escolhas políticas), pelos fluxos globais (escapam do controle social), ou pelas novas tecnologias que implicam a atuação do Estado, como é o caso da Surveillance (são incompreendidas ou simplesmente ignoradas em razão dos benefícios). Não são temas novos os desafios à democracia, mas igualmente, nunca se percebeu uma quadra da história

15 Neste sentido, Frank Richard Pfetsch (1998, p. 114) afirma que: “A capacidade de atuação do Estado está ao mesmo tempo erodida e reforçada. Com prudente otimismo, pode-se admitir que a política corporativa no plano interior e a international governance no plano externo recuperam a perda de operacionalidade decorrente dos processos indicados e até mesmo expandem a capacidade de agir. $O$ espaço de atuação do Estado não foi, afinal, meramente restrito, mas deslocou-se. Modelos de política transformaram-se e passaram a outras arenas. Falo aqui da tese do deslocamento - e não de decadência, mas sim de um deslocamento dos espaços de atuação do Estado - que se pode formular, também, como evolução da forma (Maintz).”.

16 "Aqueles que anunciam o fim do Estado-nação presumem, com freqüência (sic), a erosão do poder do Estado em razão das pressões da globalização, e não percebem a persistente capacidade que têm os Estados de formular as orientações políticas nos planos doméstico e internacional. O grau de 'autonomia' do Estado moderno em distintas condições não tem sido devidamente apreciado; em conseqüência (sic), as bases para uma análise rigorosa e sistemática da forma e dos limites das modernas democracias são negligenciadas. Claramente, o impacto dos processos globais variam de acordo com as condições internacionais e nacionais." (HELD, 1991, p. 164). 
com tanto impacto, percorrendo da primavera árabe às controversas eleições de ultranacionalistas pelo mundo. Neste sentido, é necessário compreender o motivo pelo qual o Estado ainda não percebe a complexidade e a amplitude da Surveillance, bem como a insuficiência do Direito neste cenário.

\section{SURVEILLANCE: A QUESTÃO NÃO COMPREENDIDA PELO ESTADO CONTEMPORÂNEO}

As dificuldades do Estado são claras nos diversos cenários apresentados, porém este conseguia, de toda sorte, um melhor posicionamento quando da referida modernidade sólida ${ }^{17}$, pois embora a cisão espaço-tempo já se apresentava como um aguilhão, ainda existia uma singela metricidade. $\mathrm{O}$ grande papel de provedor de certezas à sociedade, e sua dificuldade de impor uma agenda frente a agenda econômica global do capitalismo, são os resultados claros de uma insuficiência ainda maior. Em que pese, os Estados considerados desenvolvidos possam aparentemente não apresentar um impacto em grande escala, em verdade também não conseguem como os demais lidar com os desafios de forma satisfatória.

O cenário tecnológico, característica fundamental da modernidade líquida, seja por sua concomitância, seja por seu predicado de não se fixar em nenhum lugar e se moldar à todos os espaços. Estas desestabilizações são fruto de enormes questionamentos das respostas democráticas, bem como no âmbito da insuficiência de regulação pelo Direito estatal. Não obstante, muitas destas tecnologias são oriundas dos próprios Estados, mas que rapidamente fogem ao seu controle como por exemplo a DeepWeb ou Rede TOR ${ }^{18}$ (Internet Profunda).

Um apontamento importante sobre o panorama é realizado por Menezes Neto (2006b) ao reconhecer que a grande dificuldade do Estado frente aos novos desafios é ter um "olhar do novo como novo" (a capacidade de liquefazer das Novas Tecnologias da Informação), e não apenas tentar incorporar ao seu portfólio tradicional. Esta nova onda da globalização, a sociedade da informação (CHEVALLIER, 2009) coloca em lados distintos Sociedade e Estado, pois como é o caso da Google e da República Popular da China, onde esta exigiu a censura de determinados sítios em seu sistema de busca. ${ }^{19}$

17 “A lógica do poder e a lógica do controle estavam fundadas na estrita separação entre o 'dentro' e o 'fora' e em uma vigilante defesa da fronteira entre eles. As duas lógicas, reunidas em uma, estavam incorporadas na lógica do tamanho, organizada em torno de um preceito: maior significa mais eficiente. Na versão pesada da modernidade, o progresso significava tamanho crescente e expansão espacial. ” (BAUMAN, 2001, p. 133-134).

18 A denominada internet profunda, DeepWeb ou mesmo Rede TOR (THE ONION ROUTER), dizem respeito a uma Rede paralela ao funcionamento dos Navegadores WWW (Web) comuns e se caracteriza como um local de extremo anonimato e de enorme dificuldade de rastreamento. Outro ponto importante que merece destaque é que cada membro da rede (dispositivo conectado) funciona como um Servidor/Roteador da própria Rede TOR, por este motivo é conhecida como Rede Cebola em que são várias camadas sobrepostas que impedem um rastreamento por exemplo de IP (Protocolo de Internet), algo como um endereço do dispositivo conectado (notebook, smartphone, televisores). Ademais, a Rede TOR foi criada pelo Departamento Naval estadunidense, com objetivo de tornar seguras suas transmissões, posteriormente foi utilizada para permitir que cidadãos de Estados que controlam a internet, transmitam suas comunicações.

19 De acordo com Jacques Chevallier (2009, p. 35, grifo do autor): "[...] a internet constitui a prefiguração dessas que serão as 'autoestradas da informação' do futuro: sistema de circulação de informação aberta, constituída a partir da interconexão de redes de computadores, a internet é 'rede sem coração, nem senhor'; por essência mesmo deslocalizada, a sua característica é ignorar fronteiras, de abolir distâncias, permitindo aos usuários ter acesso livremente à informação disponível no mundo inteiro. Sem dúvida, alguns dispositivos foram introduzidos pelos 
Ocorre que, do mesmo modo que as informações (saber) circulam por todo o globo em velocidades inimagináveis e que existam até mesmo conflitos (poder) entre os Estados e suas Sociedades como no referido caso, há problemas superiores a estes para Teoria do Estado e também para os Direitos Individuais. "A relação entre saber e poder não é novidade, mas, atualmente, está sendo completamente redesenhada ou mais precisamente, elevada a pontos inimagináveis." (MENEZES NETO, 2016b, p. 72). Neste vácuo de poder ou neste espaço simulacro de poder, houve o estabelecimento de gigantes privadas da tecnologia que passaram a dominar instrumentos muito mais eficazes, que por vezes, compartilham com os Estados (quando lhe aprouver), e passam a ser detentoras da informação.

Os Estados, acostumados às antigas tecnologias de vigilância, próprias da modernidade sólida, se deparam com a sofisticação da Surveillance ${ }^{20}$, que deve ser compreendida como vigilância e controle, e não apenas pela possível tradução literal de vigilância. "Tradicionalmente, os estudiosos da vigilância focaram-se em quatro vertentes principais de relação, todas elas conectadas à noção de modernidade sólida: ao Estado-nação; à burocracia; à lógica tecnológica e à economia política." (MENEZES NETO, 2016b, p. 93). Sendo assim, a dimensão da tecnologia como parte indistinguível da vida em sociedade, não recebe a atenção imprescindível no conceito tradicional de mera vigilância, pois é tratada como um meio e não como um fim, conforme a compreensão da amplitude da Surveillance.

Os teóricos dos estudos da surveillance entendem, corretamente, que ela é um fenômeno complexo. Como resultado, a conotação de "detentores do poder" não deve adquirir traços panópticos ou necessariamente orwellianos. Não há razões para acreditar na existência de um poder "maligno", centralizado e capaz de coordenar uma única prática de surveillance. Não se trata de um fenômeno "essencialmente" negativo, especialmente se for compreendido como parte integrante do cotidiano, como forma inescapável de mover-se num mundo cada vez mais conectado. (MENEZES NETO, 2016a, p. 34, grifo do autor).

O fenômeno, como referido, é extremamente complexo e o Estado ao mesmo tempo em que se serve deste fluxo de informações - dados e metadados ${ }^{21}$-, esbarra igualmente em uma tentativa clara de controle. Os efeitos, notadamente, não são sentidos apenas pelos Estados em sua ineficiência, mas ao mesmo tempo, observáveis nos seus nacionais (aqueles nos quais o Estado tem seu compromisso primevo), pois a temática em uma primeira resposta, não está diante de liberdades positivas como as dos antigos, mas sim, das liberdades negativas dos modernos (CONSTANT, 1819). ${ }^{22}$ "O Estado - e o direito dele originado - parece incapaz de resolver, Estados para controlar e, mesmo barrar a circulação do fluxo de informações [...]".

20 Segundo Elias Jacob de Menezes Neto e Jose Luis Bolzan de Morais (2013, p. 895): "Preferiu-se utilizar o vocábulo em inglês em virtude dos problemas que conclusões equivocadas das traduções literais - vigilância, fiscalização, supervisão, olhar - poderiam resultar. Além disso, a grande maioria das obras dedicadas ao estudo do tema é em língua inglesa.”.

21 Metadados são todas as informações sobre os dados (dados sobre dados), como horário, localização, frequência. No fenômeno da Surveillance essas informações podem ser mais relevantes que os próprios dados.

22 "Assim, entre os antigos o indivíduo quase sempre soberano nas questões públicas, é escravo em todos seus assuntos privados. Como cidadão, ele decide sobre a paz e a guerra; como particular, permanece limitado, observado, reprimido em todos seus movimentos; [...]. Entre os modernos, ao contrário, o indivíduo independente 
exclusivamente, os problemas oriundos da violação de direitos fundamentais pelas técnicas de surveillance." (MENEZES NETO, 2016a, p. 51, grifo do autor). Embora, alguns Estados possam estar neste panorama como mentores, estes também não conseguem garantir aos seus nacionais as mesmas condições que outros tantos mais fragilizados.

O déficit democrático produzido é a marca latente do fenômeno da Surveillance, pois mesmo que seja uma ferramenta, muitas vezes, estatal, frequentemente é utilizada sem qualquer transparência, muito antes pelo contrário, marcada por muito segredo como é o caso da composição e funcionamento da Rede TOR. No entanto, como no caso da referida rede, onde os EUA utilizavam para segurança de suas comunicações militares e, depois para interesses geopolíticos, pois permitia muitas vezes que opositores de Estados considerados inimigos pelos estadunidenses burlar as restrições de acesso e comunicações imposta à internet, é possível perceber que os mesmos desenvolvedores perderam qualquer espécie de influência/controle/autoridade. Corroborando, Menezes Neto esclarece que:

O poder público, contudo, não é o único a empregar práticas de surveillance. A utilização dos bancos de informações pessoais pelos poderes privados é cada vez maior. Não se está falando apenas das empresas cuja especialidade é prestar serviços dessa natureza para o Estado, mas, muito além disso, de praticamente todos os serviços utilizados pelos indivíduos no seu cotidiano: operações financeiras, viagens, telefonia móvel, internet etc. Dos hábitos de compras à geolocalização por satélites transmitida pelos seus smartphones, a quantidade colossal de informações individualizáveis, utilizadas abertamente para fins publicitários, permitem a criação de data-doubles ${ }^{23}$, ou seja, de versões digitalizadas do ser humano que contém todas as informações por ele disponibilizadas de maneira consciente ou não. (MENEZES NETO, 2016a, p. 40, grifo do autor).

Muitos Estados ainda não conseguiram compreender que sua centralidade no cenário não é mais desejada/desejável, que a tecnologia permitiu que essa coleta de dados não se dê apenas por intermédio dos conhecidos bancos de dados oficiais. Ademais, em especial aos poderes privados, algo que pode ser considerado muito mais valioso foi inserido nesta relação, qual seja, os metadados (registros que podem ser utilizados para traçar perfis dos mais diversos interesses). O impacto deste contexto é desastroso nos direitos fundamentais, no Estado e na democracia, eis que os poderes privados passam a dominar um campo altamente especializado e que foge indubitavelmente da perspectiva de regulação no curto prazo.

É evidente que os impactos sociais deste problema ainda não foram experimentados em sua plenitude, mas apenas o potencial já é verdadeiramente assustador. Empresas como Facebook,

na vida privada, mesmo nos Estados mais livres só é soberano em aparência. Sua soberania restrita quase sempre interrompida; [...].”(CONSTANT, 1819, p. 3).

23 Em se tratando os eventuais riscos e das consequências, destaca-se no mesmo sentido que: “A formação desses data-doubles pela iniciativa privada permite o desenvolvimento de técnicas de classificação social das pessoas em determinadas categorias, o que pode resultar em novas práticas de discriminação social e violação da igualdade. Essas práticas, embora tornem o ser humano transparente ao olhar dos poderes econômicos, turvam a situação inversa, ou seja, criam relações assimétricas - e, portanto, antidemocráticas - de visibilidade, controle e poder." (MENEZES NETO; MORAIS, 2013, p. 897, grifo do autor). 
Google, Microsoft, Apple, Samsung e Sony (rol meramente exemplificativo) dispõe a cada dia de mais informações (dados e metadados) de seus consumidores. "Por sua vez, a surveillance ultrapassa a barreira do tempo real (presente), além de utilizar dados coletados no passado para interferir a possibilidade de um evento no futuro." (MENEZES NETO, 2016b, p. 99, grifo do autor). Assim, estas informações circulam com velocidade inimagináveis e são compartilhadas com governos, quando interessa às gigantes da tecnologia. "Contudo, os critérios de coleta, análise e classificação das informações são opacos, especialmente em razão de se tratarem de conhecimentos eminentemente técnicos e, portanto, de difícil compreensão por leigos." (MENEZES NETO; MORAIS, 2013, p. 900, grifo do autor).

A incapacidade dos Estados em controlar este cenário, inaugura parcerias nefastas e escusas, onde se privatiza de maneira sutil as funções inerentes ao Estado, em nome do compartilhamento destas informações. Como referido acima por Menezes Neto (2016b), se está diante de algo que não pode ser entendido apenas de maneira negativa, ou mesmo não se pode compreender com as lentes do passado, do velho Estado territorializado. Mas, é indispensável "[...] reelaborar um modelo de controle do exercício dos poderes associados à tecnologia da informação que colocam em risco os direitos fundamentais e a democracia." (MENEZES NETO; MORAIS, 2013, p. 898, grifo do autor). É, por este motivo, que se faz necessário avançar nas questões que envolvem uma melhor compreensão da tecnologia e a dimensão de risco associado, pois como já mencionado os indivíduos são a fonte crescente e voluntária de cessão destas informações.

\section{RISCO E TECNOLOGIA: DIANTE DA (IN)DISSOCIABILIDADE DOS ACONTECIMENTOS FRENTE A AMBIVALÊNCIA DA TÉCNICA}

A Modernidade em toda sua perspectiva (Sólida/Líquida), trouxe uma aproximação conceitual da dimensão do Risco, que por muitos foi inicialmente confundida com a ideia de perigo de sociedades pré-modernas, pois embora estejam “[...] intimamente relacionados, [...] não são a mesma coisa. A diferença reside em se o indivíduo pesa ou não conscientemente as alternativas ao contemplar ou assumir uma linha de ação específica." (GIDDENS, 1991, p. 45). O risco é um fenômeno moderno e portanto influente e influenciado no modelo econômico capitalista e pelos fluxos e influxos da globalização.

Os Estados também estão adstritos à necessidade de compreensão do conceito/contexto em que o risco se intermedeia, pois é um cenário não muito claro devido a sua complexidade. A função protetora/provedora assumida pelo Estado, o garantidor de certezas é seguramente colocada em xeque diante de um panorama de risco na contemporaneidade. Os meios pelos quais os Estados intervêm na questão, também não correspondem de maneira adequada, pois não há uma arquitetura supranacional ou cooperacional. Ocorre que, para Ulrich Beck os:

[...] riscos são inicialmente bens de rejeição, cuja inexistência é pressuposta até prova em contrário - de acordo com o princípio: "in dubio pro progresso", e isto quer dizer: na dúvida, deixa estar. [...] Os riscos podem ser legitimados pelo 
fato de que sua produção não foi nem prevista, nem desejada. As situações de ameaça precisam, portanto, na civilização cientificizada, romper o privilégio da tabularização que as cerca e "nascer cientificamente". (BECK, 2011, p. 41, grifo do autor).

O problema da disciplina dos riscos (em geral), é justamente o mesmo do identificado na Surveillance (em específico), o Estado tenta resolver questões desterritorializadas com o direito territorial. Não há como se afastar completamente do panorama, eis que em maior ou menor medida todos serão atingidos se agirem com a racionalidade da modernidade sólida. "O efeito bumerangue também acaba por afetar países ricos, que justamente se haviam livrado dos riscos através da transferência [...]" (BECK, 2011, p. 53), mas que em alguma medida terão o retorno dentro de suas fronteiras ${ }^{24}$.

Este processo é acelerado, de toda sorte, quando o capitalismo e a globalização atingem um nível mais elevado de entrelaçamento, permitindo que se insiram avanços tecnológicos que alargariam os contextos até então vigentes. Embora Ulrich Beck possa ter objeções críticas acerca de sua concepção e extensão do Risco ${ }^{25}$, em especial por Zygmunt Bauman com aponta Menezes Neto (2016b), não se pode olvidar que o ponto de ancoragem apresentado para uma construção de Sociedade de Risco é extremamente relevante. Este esqueleto teórico desenvolvido, estabelece uma cristalina junção entre Tecnologia e Risco, além de identificar os referidos contributos do capitalismo e da globalização para o aprofundamento das desigualdades sociais.

A ciência na contemporaneidade já bastante colonizada pela técnica, aqui entendida de caráter potencialmente à serviço do capitalismo globalizado, expõe a fragilidade estatal, pois este não mais está na vanguarda da pesquisa científico-tecnológica, se é que em algum momento esteve. Assim como referido anteriormente em relação à surveillance, a técnica/tecnologia também não pode ser demonizada ou negativada. "O aspecto ambivalente de toda ação técnica passou a implicar na impossibilidade de se distinguir e separar os efeitos bons e maus.” (BARRETTO, 2013, p. 322). Todavia, é imperativo perceber que igualmente como ocorre naquela, há uma intensa redução na participação decisória da sociedade, pois decisões técnicas ficavam frequentemente adstritas aos campos da ciência tecnicizada, sendo a Sociedade e o Estado meros espectadores.

Contudo, há uma singela modificação, pois "[...] se as pessoas vivenciam os riscos como algo real, eles são reais. Se eles são, contudo, reais nesse sentido, eles reviram a estrutura de competências sociais, políticas e econômicas.” (BECK, 2011, p. 95, grifo do autor). Assim, é possível identificar as razões das crises que o Estado está enfrentando, mas igualmente, há outros riscos oriundos dos processos tecnológicos, que sequer são meramente percebidos pela sociedade ou regulados pelo Estado, como é o caso da Surveillance.

Quando se está diante dos riscos (aqui entendidos como fenômenos da modernidade),

24 “A única proteção realmente eficaz sob essas condições seria não comer, não beber, não respirar. E mesmo isto ajuda apenas em parte." (BECK, 2011, p. 43, grifo do autor).

25 "O núcleo da consciência do risco não está no presente, e sim no futuro. Na sociedade de risco, o passado deixa de ter força determinante em relação ao presente. Em seu lugar, entra o futuro, algo todavia inexistente, construído e fictício como 'causa' da vivência e da atuação presente." (BECK, 2011, p. 40, grifo do autor). 
também se está diante de um processo desigual de redistribuição, tendo em vista que não obedece a mesma lógica da distribuição da riqueza. Ao mesmo tempo, é necessário discordar de algumas afirmações de Ulrich Beck (2011), pois não se pode conferir a mesma intensidade à quaisquer indivíduo independente de sua condição social, tendo em vista que embora seja impossível controlar seus efeitos como nas questões ambientais, os mais dependentes do Estado Social serão os mais fragilizados, inaugurando mais uma das crises mencionadas.

É indubitável que seja denominada de Sociedade de Risco (BECK, 2011) ou Sociedade da Técnica (BARRETTO, 2013), o momento do paradigma moderno que não se afasta da Tecnologia e, por tudo que já foi mencionado, a mesma igualmente não se percebe sem a presença do Risco. A potencialidade que a tecnologia dispõe frente aos controles que à ela são possíveis é quase identificável com uma disputa entre uma arma de brinquedo e uma bomba de hidrogênio. A presença dos ditames do capitalismo financeiro global na condução da ciência, ora tecnicizada, e o alargamento e popularização das mais diversas ferramentas tecnológicas são o espectro mais contundente que fenômenos com aportes tecnológicos como a Surveillance são promotores do risco. Afinal,

"[...] a surveillance é um fenômeno incapaz de ser reduzido a uma série de conceitos e, atualmente, só encontra dois limites, a saber, a capacidade técnica dos seus instrumentos e a criatividade dos indivíduos para criar novos sistemas de categorização e análise de dados." (MENEZES NETO, 2016a, p. 47, grifo do autor).

Assim, a equação estabelecida é bastante fulgurante, pois as novas tecnologias da informação se ampliam na medida que os recursos investidos em seu desenvolvimento também se dilatam. Quando aplicadas à Surveillance, é possível perceber que estes recursos tecnológicos não estão exclusivamente de posse dos Estados e, muitos inclusive estão totalmente alijados, sendo apenas destinatários dos riscos. "As práticas da surveillance, auxiliadas pela tecnologia de informação, tornam visíveis mais dados ao pequeno grupo que dispõe de recursos econômicos e técnicos para processá-los." (MENEZES NETO, 2016a, p. 47, grifo do autor). Permitindo que o cenário seja rapidamente consolidado em alguns poderes privados, de igual sorte promotores dos mais diversos riscos.

A tentativa frustrada de compreender a Surveillance como mera vigilância, de não identificar as relações entre Risco e Tecnologia, bem como não reconhecer as limitações da territorialidade fazem com que o Estado aprofunde as crises funcional e política. Este contexto, reserva uma necessidade de identificar novos caminhos à reconstrução democrática de um controle social destas práticas, com vistas até mesmo a legitimar as medidas do Estado e conformar a Teoria do Estado na contemporaneidade. Desta maneira, é importante um encerramento, mesmo que provisório da discussão, no âmbito das possibilidades de uma solução democrática aos desafios impostos, pois relegar estas decisões aos denominados poderes privados é abandonar a própria necessidade de debater o Estado. 


\section{OS FLUXOS GLOBAIS E A FRAGILIDADE DA TERRITORIALIDADE ESTATAL: POR UMA SOLUÇÃO DEMOCRÁTICA AO CENÁRIO DE CRISE}

Os desafios oferecidos pela Surveillance, como já referido, assentam o Estado como incapaz de responder regulatoriamente no âmbito do seu direito interno, pois o fenômeno escapa à um racionalismo territorializado. Alguns Estados se serviram, e ainda se servem dos denominados poderes invisíveis contra seus próprios cidadãos, o que de toda sorte é incompatível com uma democracia, sendo um dos maiores enigmas assentados na modernidade líquida. Ademais, não se pode esquecer das parcerias com entidades (poderes) privados na prática da vigilância e controle, mas indubitavelmente o resultado, o produto destas práticas se transforma em algoritmos que o Estado não tem acesso e a sociedade sequer desconfia da sua existência.

Os gigantescos bancos de dados/metadados organizados pelos poderes privados são de potencial ainda inimaginável, pois de plano é simples compreender que os indivíduos segundo a lógica capitalista ou são (possíveis) consumidores ou não interessam. Da mesma forma, operam os Estados, em especial em casos de segurança interna contra o terrorismo - onde a Surveillance é utilizada frequentemente -, ou os indivíduos são (potenciais) agressores ou não. Ambos, podem classificar, catalogar e traçar perfis das pessoas, sem qualquer participação democrática, além de transformar em códigos computacionais que passarão a operar em um modelo predeterminado e oculto da sociedade.

Todavia, embora os Estados sejam usuários, o código fonte é do poder privado, que busca a todo momento se afastar de quaisquer regulamentações de ordem democrática e, por vezes, propondo até mesmo a forma de regulação via indicadores ou standards internacionais, sob os quais possuem grande influência. "O direito justo, por seu turno, não pode ser responsabilidade das partes afetadas, mas de poderes 'públicos' comuns, de um Estado em sentido lato.” (HÖFFE, 2005, p. 502, grifo do autor). Não obstante, este fato é conducente da Crise Institucional e Funcional do Estado, bem como um grande promotor de desigualdades por estas classificações de indivíduos (MENEZES NETO, 2016b).

É preciso ter presente, que embora o Estado não compreenda a plenitude da Surveillance e os riscos inerentes à democracia, este não pode abdicar às promessas assumidas, em especial em relação as liberdades (negativa e positiva). ${ }^{26}$ "La importancia y el atractivo de la idea del Estado moderno residen en la noción de un sistema de poder circunscrito cuyo cometido es respaldar un conjunto específico de regulaciones y controles que se impone a gobernantes y gobernados por igual." (HELD, 1997, p. 181). Todavia, escapam destes controles por força da globalização alguns dos principais atores da Surveillance, as transnacionais da tecnologia da informação e comunicação. Com isto:

26 Segundo Hans Kelsen (2000, p. 278): “A liberdade negativa, essencial à democracia moderna, existe na proibição constitucional de qualquer ato [...] restrinja [...] liberdades ou direitos humanos que uma constituição deve garantir para ser considerada democrática [...]". 
[...] a lei assegura a extensão e a controlabilidade do poder público e, portanto, delimita exatamente suas competências." Assim, a ação estatal é rigidamente planejada pela lei, que estabelece fins, regras e deveres para o poder público. Esse é o modelo do poder legal-racional, previsível, mensurável, e, portanto, controlável. Do lado oposto, os sujeitos privados agem de acordo com interesses e objetivos próprios, visto que a lei define apenas o que lhes é vetado. (CASSESE, 2010, p. 137).

A grande dificuldade de levar a efeito a constatação do autor, se traduz justamente na fluidez diversamente mencionada ao longo do presente. Além disto, a repetitiva resposta territorializada do Estado, está sistematicamente ignorando que os indivíduos também necessitam participar deste processo. Afinal, são eles os diretamente atingidos, bem como os grandes fornecedores, voluntários, de seus dados/metadados. Embora, seja manifesto que "[...] el Estado moderno se desarrolló como Estado-nación bajo la forma de democracia representativa liberal, y cómo este tipo de democracia llegó a predominar en el mundo político.”(HELD, 1997, p. 75).

A democracia moderna alcançou seu ápice ao passo que também percebeu sua insuficiência na territorialidade, pois foi possível perceber que não só a participação política era mote único e indispensável. "El desarollo en el largo plazo de mecanismos de democracia directa también participó de ese movimiento de concentración, al presuponer que la plena realización del ideal democrático [...]" (ROSANVALLON, 2010, p. 297). Neste sentido, a força motriz na qual se está esquadrinhando a mudança, é a concepção de autonomia do individuo no exercício democrático.

La idea de autonomía implica que el ejercicio de la capacidad individual debe estar exento de restricciones inadecuadas - políticas, sociales e económicas - y que la autonomía debe ser articulada en términos de disposiciones que garantizan la autonomía de todos los miembros de la comunidad política. En consecuencia, la autonomía descansa tanto la habilitación como en la restricción; debe ser sustentada y limitada en su proprio nombre.(HELD, 1997, p. 265-266).

Em sentido contrário é possível identificar que “[...] la teoría democrática moderna se ha preocupado sobre todo por las condiciones que fomentan o entorpecen la vida democrática de una nación." (HELD, 2012, p. 407). Mas, o que se pretende é compor uma nova possibilidade de refletir sobre a democracia que não seja sob a concepção do Estado Territorial. Por evidente, não se pretende amparar uma eventual superação do modelo estatal (um fim do Estado), mas de outra banda construir horizontes possíveis ao enfrentamento dos fluxos globais com soluções democráticas. Afinal: "La consolidación del derecho público democrático es la fundación de la autonomí; promete protección y seguridad a todas y cada una de las personas que acepten su regulación." (HELD, 1997, p. 266).

Refletir sobre a democracia para além do Estado não é necessário superá-lo, mas ao mesmo é indispensável reconhecer que o enfrentamento da Surveillance não pode como referido por diversos momentos ser pensado sob o prisma da solidez da modernidade (ou parte dela) de outrora. A construção da democracia moderna se deu no interior dos Estados (de maneira conturbada 
e complexa) e, é com esse suporte que poderá ser alargada além fronteiras. ${ }^{27}$ Conquanto alguns autores como Otfried Höffe (2005) e David Held ${ }^{28}$ (1991, 1997, 2012) desenvolvam concepções para além do Estado ou mesmo cosmopolitas de democracia, não há um cambio de horizontes possível, partindo de outro local que não seja o próprio Estado. Isto resta evidente quando Höffe se refere a República Mundial, pois:

Na edificação da estrutura global de Direito e Democracia, ela representa o último módulo, ela é o teto da coroa a construção. E se houver falhas na alvenaria, se houver graves deficits no tocante ao caráter de Estado de Direito e Democracia, a República Mundial auxiliará os Estados Nacionais. Mas não se deve esperar seu êxito com impaciência, querendo que tudo aconteça "de hoje para amanhã". (HÖFFE, 2005, p. 507).

De outra banda, é importante destacar que mesmo superando todas estas eventuais barreiras à construção de uma democracia para além das fronteiras do Estado, não se pode olvidar que os poderes invisíveis exercidos pelos grandes conglomerados da tecnologia podem reagir. A reação dos poderes privados é em busca da manutenção do status quo, eis que as práticas da Surveillance lhes permitem ampliar sua influência e os lucros. Este efeito ricochete é o que Menezes Neto (2016b) denomina de filtro bolha, a informação que atinge o indivíduo é aquela que os poderes privados selecionam.

Assim, os elementos essenciais a democracia (visibilidade e accountability) restam prejudicados, com a capacidade das novas tecnologias da informação e comunicação à serviço da Surveillance, em nome da manipulação política e econômica. "Tal fato se dá porque a 'transparência' democrática, que permite a accountability dos detentores do poder, é diametralmente oposta à visibilidade proporcionada pela surveillance. (MENEZES NETO, 2016b, p. 199). É neste sentido, que se deve compreender que as insuficiências do Estado frente ao fenômeno devem ser superadas em conjunto com os indivíduos democraticamente.

\section{CONSIDERAÇÕES FINAIS}

Algumas das reflexões deslindadas no presente não são novidades nas discussões sobre a estatalidade, mas de outra banda estão longe de alcançar um consenso, seja na Teoria do Estado, seja em outro panorama possível. Fica evidente que as Crises do Estado, apresentadas por Morais $(2005,2011)$ são indispensáveis para pensar um futuro do Estado, bem como da própria Teoria

27 “Assim como se construiu paulatinamente a democracia dentro dos Estados-Nações, envolvendo um processo conflituoso e lento de extensão dos direitos e da participação política dos cidadãos, hoje esse processo começa a ocorrer no plano mundial, envolvendo a busca de ampliação dos direitos e da participação política dos Estados-

Nações no planeta Terra." (FORJAZ, 2000, p. 48)

28 Todavia, David Held (1991, p. 179) adverte: "Mesmo que a teoria da democracia já não possa ser elabora tãosomente como teoria da comunidade política territorialmente delimitada, o Estado-nação não pode ser posto de lado como um ponto de referência central. Os processos globais não podem ser exagerados a ponto de eclipsar inteiramente o sistema de Estados ou de confundir-se simplesmente com a emergência de uma sociedade mundial integrada." 
do Estado. Neste sentido, é importante destacar que em maior ou menor medida as crises não são exclusivas de Estados pequenos ou grandes, desenvolvidos ou em desenvolvimento, pois atingem a todos de alguma maneira.

Ademais, não se pode olvidar que estes desafios ao Estado são constantes e remontam ao próprio surgimento do mesmo enquanto instituição político-jurídica da modernidade, pois muitas das promessas estabelecidas por ela, ficaram a cargo dele. Além disto, se percebe que o modelo econômico capitalista e o processo (múltiplos processos) de globalização também impuseram novos desafios à estatalidade, que por sua vez tenta sistematicamente regredir à sua cooriginaridade da modernidade sólida.

A soberania não compartilha de seu conceito de outrora, não é apenas no território que os desafios aos Estados estão localizados, as fronteiras de toda sorte são meras exclusões geográficas, servindo apenas de referência para fenômenos físicos. Os fluxos globais não respeitam a lógica do território e da fronteira, pois estão sob uma nova perspectiva da modernidade, sua feição líquida, ou seja, muros e guardas não podem impor restrições significativas como pensam alguns líderes mundiais, ainda hoje.

O avanço no campo da tecnologia (Novas Tecnologias da Informação e Comunicação) espraiaram novamente a insuficiência regulatória do Estado Moderno (Sólido). Com isto, insurge a Surveillance, inicialmente como fenômeno constituído pela própria estatalidade (algumas), mas que rapidamente fogem ao seu controle, pois o Estado entendia a mesma como ferramentas de mera vigilância. Os riscos e a tecnologia são imbricados, não há como dissociar, assim como a Surveillance, a técnica aplicada à ciência é ambivalente, nem boa, nem ruim, ao passo que saída "[...] capaz de encerrar e processar os riscos chama-se: crítica da ciência, crítica do progresso, crítica dos especialistas, crítica da tecnologia.” (BECK, 2011, p. 241).

De toda sorte, restou por evidente que os problemas com a Surveillance alteram consideravelmente as relações sociais, pois os poderes invisíveis estão à serviço dos poderes privados e que os próprios indivíduos fazem questão de alimentar por pura ignorância. Os Estados também não os enfrentam na sua totalidade por não compreenderem ou por não lhes interessar, mas ao certo é que as desigualdades sociais (atualmente apenas em potencial) que podem decorrer são devastadoras.

Com efeito, o Estado, de alguma maneira estático frente as práticas da Surveillance na contemporaneidade, tende por expandir a relativização democrática, eis que os poderes privados, detentores da tecnologia, por diversas razões não comportam práticas democráticas em seu sentido estatal. É necessário compreender que o Estado é muito importante para o exercício democrático, mas nesta quadra, também é igualmente indispensável integrar novos sistemas democráticos. É preciso repensar o Estado e a Teoria do Estado, com vistas à que possam compreender um cambio de horizontes possível, eis que os problemas como a Surveillance não são meramente potenciais, são reais e atuais.

\section{REFERÊNCIAS}


AVELÃS NUNES, António José. Do estado liberal à "revolução Keynesiana". 2007. Disponível em: http://www.odiario.info/b2-img/avelasnunes.pdf. Acesso em: 7 jul. 2017.

BARRETTO, Vicente de Paulo. O fetiche dos direitos humanos e outros temas. 2. ed. Porto Alegre: Livraria do Advogado Editora, 2013.

BAUMAN, Zygmunt. Globalização e as consequências humanas. Tradução de Marcus Penchel. Rio de Janeiro: Zahar, 1999a.

BAUMAN, Zygmunt. Modernidade e ambivalência. Tradução de Marcus Penchel. Rio de Janeiro: Zahar, 1999b.

BAUMAN, Zygmunt. Modernidade líquida. Tradução de Plínio Dentzien. Rio de Janeiro: Zahar, 2001.

BECK, Ulrich. Sociedade de risco: rumo a uma outra modernidade. Tradução de Sebastião Nascimento. 2. ed. São Paulo: Editora 34, 2011.

BONAVIDES, Paulo. Do estado liberal do estado social. 10. ed. São Paulo: Malheiros Editores, 2011.

CASSESE, Sabino. A crise do estado. Tradução de Ilse Paschoal Moreira e Fernanda Landucci Ortale. Campinas: Saberes Editora, 2010.

CHEVALLIER, Jacques. O estado pós-moderno. Tradução de Marçal Justen Filho. Belo Horizonte: Fórum, 2009.

CONSTANT, Benjamin. Da liberdade dos antigos comparada à dos modernos. Discurso pronunciado no Athénée Royal de Paris, 1819.

FORJAZ, Maria Cecília Espina. Globalização e crise do estado nacional. Revista de Administração de Empresas, São Paulo, v. 40, n. 2, p. 38-50, 2000.

GIDDENS, Anthony. As consequências da modernidade. Tradução de Raul Ficker. São Paulo: Editora UNESP, 1991.

GIDDENS, Anthony; LASH, Scott; BECK, Ulrich. Modernização reflexiva: política, tradição e estética na ordem social moderna. Tradução de Magda Lopes. São Paulo: Editora UNESP, 2012.

HARDT, Michael; NEGRI, Antonio. Império. Tradução de Berilo Vargas. 3. ed. Rio de Janeiro: Editora Record, 2001.

HELD, David. A democracia, o estado-nação e o sistema global. Lua Nova, São Paulo, v. 41, n. 23, p. 145-194, 1991.

HELD, David. La democracia y el ordem global. Traducción de Sebastián Mazzuca. Barcelona: Paidós, 1997.

HELD, David. Modelos de democracia. Traducción de María Hernández Díaz. 3. ed. Madrid: Alianza Editorial, 2012. 
HÖFFE, Otfried. A democracia no mundo de hoje. Tradução de Tito Lívio Cruz Romão. São Paulo: Editora Martins Fontes, 2005.

KELSEN, Hans. A democracia. Tradução de Ivone Castilho Benedetti, Jefferson Luiz Camargo e Vera Barkow. 2. ed. São Paulo: Editora Martins Fontes, 2000.

MENEZES NETO, Elias Jacob. Os limites do estado e do regime democrático no controle da surveillance. In: MORAIS, Jose Luis Bolzan; SARAIVA, Bruno Cozza. Estado e constituição. Florianópolis: Empório do Direito, 2016a. p. 33-56.

MENEZES NETO, Elias Jacob. Surveillance, democracia e direitos humanos: os limites do Estado na Era do Big Data. 2016. 293 f. Tese (Doutorado em Direito) - Universidade do Vale do Rio dos Sinos, São Leopoldo, 2016b.

MENEZES NETO, Elias Jacob; MORAIS, Jose Luis Bolzan. Direitos fundamentais, democracia e surveillance: as insuficiências do modelo estatal na sociedade em rede. In: CONGRESSO INTERNACIONAL DIREITO E CONTEMPORANEIDADE, 2., 2013, Santa Maria. Anais [...]. Disponível em: http//www.ufsm.br/congressodireito/anais. Acesso em: 7 jul. 2017.

MIRANDA, Jorge. Teoria do estado e da constituição. 3. ed. Rio de Janeiro: Forense, 2011.

MORAIS, Jose Luis Bolzan. As crises do estado e da constituição e a transformação espaçotemporal dos direitos humanos. 2. ed. Porto Alegre: Livraria do Advogado Editora, 2011.

MORAIS, Jose Luis Bolzan. As crises do estado. In: MORAIS, José Luis Bolzan (org.). O estado e suas crises. Porto Alegre: Livraria do Advogado, 2005.

PFETSCH, Frank Richard. Capacidade de atuar e legitimação do Estado democrático de direito na era da globalização. Revista Brasileira de Política Internacional, Brasília, v. 41, n. 2, p. 102-117, 1998.

ROSANVALLON, Pierre. La legitimidad democrática. Tradução de Traducción: Heber Cardoso. Madrid: Paidós, 2010.

STRECK, Lenio Luiz; MORAIS, José Luis Bolzan. Ciência política e teoria do estado. 6. ed. Porto Alegre: Livraria do Advogado, 2008.

Como citar: MARQUES, Carlos Alexandre Michaello; ROCHA, Leonel Severo. Estado, surveillance e risco: caminhos tortuosos em tempos de relativização da democracia na esteira da tecnologia. Revista do Direito Público, Londrina, v. 14, n. 2, p. 68-90, ago. 2019. DOI: 10.5433/24157-108104-1.2019v14n2p. 68. ISSN: 1980-511X

Recebido em: 14/11/2017.

Aprovado em: 08/04/2019. 